\title{
Negação e objetividade na Crítica da Razão Pura: Uma leitura da Dialética Transcendental
}

SiLVANA DE Souza Ramos*

Resumo: O artigo analisa - a partir da leitura da Dialética Transcendental - a relação entre a teoria kantiana da objetividade $\mathrm{e}$ a demarcação de um uso válido da negação na determinação de objetos.

Palavras-chave: Kant, negação, objeto, contradição, determinação.

\begin{abstract}
The article analyzes - based on a reading of the Transcendental Dialectics - the relation between Kant's theory of the objectivity and a delineation of valid use of the negativity in the determination of objects.
\end{abstract}

Key-words: Kant, negativity, object, contradiction, determination.

* Doutoranda do Departamento de Filosofia da USP e bolsista da Fapesp. 

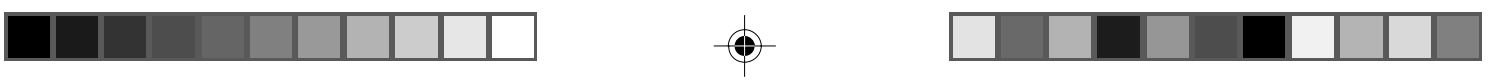

CAdernos Espinosanos XVI - 2007

Construir torres abstratas porém a luta é real. Sobre a luta nossa visão se constrói. O real nos doerá para sempre.

Orides Fontela

Numa correspondência endereçada a Garbe, Kant sinaliza para a origem do empreendimento crítico (Kant apud Lebrun, p. 95, grifo nosso):

Meu ponto de partida não foi a investigação da existência de Deus, da imortalidade, etc., mas a Antinomia da razão pura... foi ela que me despertou pela primeira vez do sono dogmático e me levou à crítica da própria razão, para fazer cessar o escândalo de uma aparente contradição da razão consigo mesma.

Este trecho é comumente citado pelos comentadores e recebe diferentes interpretações. Aos olhos de Lebrun, faltou aos leitores especificar, a partir de tais afirmações, o papel que a Antinomia adquire no interior da Crítica. Afinal, "Sem esse 'estranho fenômeno', como se poderia algum dia surpreender a metafísica em flagrante delito de erro, já que é impossível confrontar suas proposições com a experiência?" (Lebrun, p. 96, grifo nosso). Nestes termos, as antinomias têm um papel fundamental: elas "são, portanto, a única ocasião dada ao entendimento de escapar da aparência da qual ele é naturalmente vítima" (idem, grifo nosso). Se Kant fora despertado pela Antinomia, nada mais justo do que dar-lhe o devido relevo, inclusive, mostrar o seu caráter pedagógico, na medida em que o espetáculo da razão em luta consigo mesma só pode alertar para a necessidade de se reconhecer o erro que naturalmente a incita a engendrar a ilusão metafísica. 

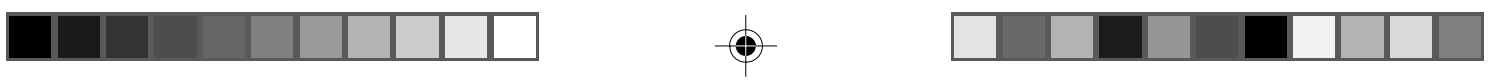

David-Ménard, por sua vez, ainda que conceda relevância central à Antinomia, encontra em sua análise a ocasião para dar fundamentação a uma leitura engenhosa da obra de Kant. Trata-se, para a autora, de salientar que a origem do empreendimento crítico não pode ser verdadeiramente compreendida se não for levada em consideração a leitura atenta que Kant fez da obra do visionário sueco Swedenborg: "ainda que não se pronuncie o nome de Swedenborg, Kant retoma com todas as letras a descrição do pensamento deste último" (David-Ménard, p. 10). Quer dizer, ao lado do inimigo explícito, a metafísica, representada sobretudo por Leibniz, há ainda um outro personagem importante, ocultado na Crítica: o sábio visionário. Deste modo, David-Ménard procura mostrar que o pensamento de Kant se volta principalmente, não para as dificuldades colocadas por Hume, mas para (David-Ménard, p. 10, grifo nosso):

essa recusa simultânea do dogmatismo e da extravagância... de um lado, a categoria do possível tem a função de reunir Swedenborg e Leibniz - estes, com efeito, invocam conceitos sem objeto que, sem serem impossíveis no sentido da contradição, não podem ser contados entre os possíveis -; de outro, a categoria do real afasta os dois autores: ao fazer da percepção um critério necessário de toda representação que pretende apreender um objeto real, Kant exclui o número leibniziano, mas, para poder excluir as visões de Swedenborg das experiências que dão acesso à realidade, logo precisa acrescentar que só podem ser ditas realidades as intuições e percepções que se encadeiem segundo os princípios a priori do entendimento puro. 

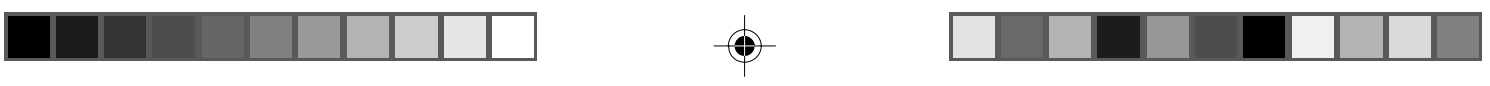

CAdernos Espinosanos XVI - 2007

Neste sentido, Kant precisa limitar o conhecimento à experiência, mas o procedimento crítico deve operar no intuito de ao mesmo tempo garantir que as leis do entendimento se apliquem a intuições. Lebrun, ao acentuar o fato de que o problema da Crítica é o da possibilidade de juízos sintéticos a priori, mostra que a solução de tal problema comanda o "destino" da metafísica inteira. Assim, "o afrontamento sem fim das teses é o signo de que vale a pena parar neste lugar - não medir os 'progressos', mas voltar ao ponto de partida" (Lebrun, p. 26), quer dizer, ao mecanismo pseudo-racional do qual nasce a ilusão metafísica, esse estranho conhecimento sem objeto. O que nos interessa é o fato de que, tanto para Lebrun quanto para David-Ménard, o problema para o qual a Antinomia nos desperta é aquele que concerne à possibilidade de um conhecimento efetivo advindo do esclarecimento crítico proporcionado pelo espetáculo da Antinomia. Cabe, pois, à Crítica responder em que sentido podemos afirmar que nossas investigações e conhecimentos de fato abarcam o real, e quando e como elas podem apontar para o ideal ${ }^{1}$.

Neste sentido, podemos notar a importância da Dialética Transcendental para a compreensão do empreendimento crítico kantiano no que diz respeito à determinação do âmbito da objetividade. Afinal, para que se constitua realmente um objeto de conhecimento, é necessário, por um lado, limitar o conhecimento à experiência (quer dizer, circunscrever seu âmbito empírico), e, por outro, operar a crítica no intuito de ao mesmo tempo garantir que as leis do entendimento se apliquem a intuições e não a fantasmas (quer dizer, é preciso demarcar a adequação na aplicação das leis do entendimento). É preciso, pois, identificar o "tropeço da razão" que induz o entendimento à síntese, a partir dos fenômenos, em direção a uma idéia - cosmológica e fantasmagórica - que ultrapassa o âmbito fenomênico, a idéia de 

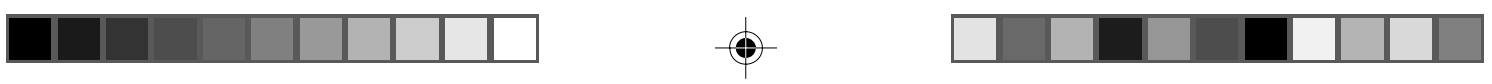

mundo (seja enquanto quantum matemático, $1^{\mathrm{a}}$ e $2^{\mathrm{a}}$ antinomias, seja enquanto totalidade dinâmica, $3^{\mathrm{a}}$ e $4^{\mathrm{a}}$ antinomias). Tal idéia é responsável pela produção e pela permanência das antinomias na medida em que impossibilita sua resolução na experiência. Kant é incisivo neste ponto: o mundo não existe, porquanto não é um objeto possível, quer dizer, jamais teremos experiência da totalidade sintética dos fenômenos capaz de nos colocar realmente diante do mundo.

Mas não é só isso, pois a investigação kantiana leva a um novo problema que completa o movimento em direção à teoria da objetividade. Trata-se de uma parte espinhosa da argumentação crítica na medida em que a estratégia kantiana, que abrirá campo à resolução das antinomias, envolve a apreciação do poder ontológico do negativo. Para entendermos este ponto, partiremos da formulação certeira de David-Ménard (p. 32-33):

... como o estudo da aparência torna necessária uma reflexão sobre o poder lógico e transcendental da negação, a oposição entre o nada e o algo consiste na maneira em que a negação intervém em nossos juízos: quando o pensamento cai sub-repticiamente numa oposição meramente dialética ou numa oposição que tem a pretensão de ser a um só tempo analítica e ontológica, ele disputa consigo mesmo a propósito de uma aparência de mundo, de uma idéia de mundo que se revela um nada do ponto de vista da existência a conhecer. Ao contrário, o entendimento conhecerá algo quando a negação for posta em jogo, à semelhança do que o juízo indefinido em lógica e a oposição real do ponto de vista epistemológico tornam possível. 

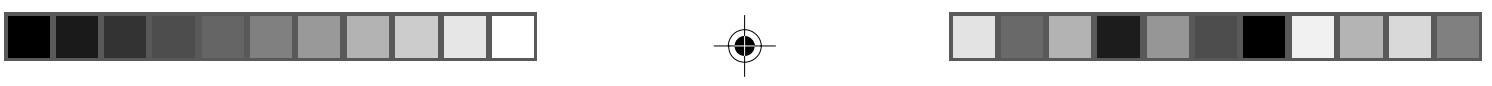

CAdernos Espinosanos XVI - 2007

A análise das antinomias mostra que a querela é um mero conflito na medida em que a idéia de mundo é um nada do ponto de vista da existência. É preciso entender, contudo, a segunda parte da argumentação de David-Ménard: que há de especial no uso da negação que pode ser útil para desvelar a falácia do conflito antinômico? Ora, o poder da negação é analisado pelo menos em dois momentos decisivos da $C R P$. Primeiramente, na "Nota sobre a anfibolia dos conceitos da reflexão", e, posteriormente, na seção 7 da Dialética Transcendental. Nos dois casos, o complexo quadro de conceitos evocados por Kant - que circunscreve o poder da negação — será capaz de enfim esclarecer os combatentes da metafísica de que sua contenda é, em termos kantianos, por nada.

\section{A falácia dos raciocínios cosmológicos}

Kant inicia a sétima seção da Dialética Transcendental relembrando que as idéias cosmológicas nascem do seguinte raciocínio: "quando o condicionado é dado, é dada também toda a série de condições do mesmo" (B 525, grifo nosso) e declara que antes de explicitar o que há de sofístico neste argumento, é preciso afirmar que ele é, em certa medida, válido e por isso irrepreensível, pois:

1) trata-se de uma proposição analítica, e nisto não há nada que se refutar à sua validade. É um postulado lógico (ligação de um conceito com suas condições) que ordena perseguir, a partir do condicionado, a série das condições, até o incondicionado (até onde for possível); 


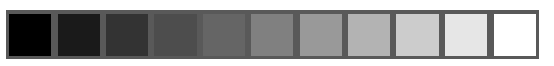

2) quando o entendimento trabalha com as coisas em si, então é possível fazer a regressão em direção à totalidade e ao incondicionado, porque realmente, neste caso, quando o condicionado é dado, a regressão à condição "não só é proposta como tarefa, como realmente dada conjuntamente" (B 427, grifo nosso). Aqui, a síntese se daria apenas no entendimento (claro, isso ocorreria se tivéssemos acesso às coisas em si, por isso Kant formula o raciocínio de maneira condicional).

Entretanto, quando aplicamos o mesmo raciocínio aos fenômenos, porque estes só se dão na síntese empírica (temporal), não obtemos o mesmo sucesso. Contudo, surge aqui a "tarefa" posta ao entendimento de seguir regredindo na série até a totalidade. Circunscreve-se então a primeira faceta do problema (B 528-9, grifo nosso):

A síntese do condicionado e da condição e toda a série das condições (na premissa maior) não implica qualquer limitação pelo tempo nem qualquer conceito de sucessão. Em contrapartida, a síntese empírica e a série das condições no fenômeno (subsumida na premissa menor) são necessariamente sucessivas e só dadas no tempo uma após a outra. Por conseguinte, não posso pressupor, nem no segundo caso nem no primeiro, a totalidade absoluta da síntese e da série que ela representa; porque, no primeiro, todos os termos da série são dados em si (sem condição de tempo), mas aqui são unicamente possíveis pela regressão sucessiva, que só é dada na medida em que realmente se efectua. 

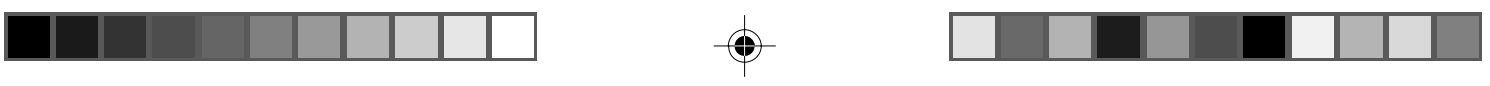

Cadernos Espinosanos XVI - 2007

A falácia consiste no fato de que a premissa maior se refere às coisas em si enquanto a menor pressupõe a síntese empírica no fenômeno. Isto impossibilita a completude da síntese, tanto numa quanto noutra. Ora, é este o vício e o fundamento das afirmações cosmológicas, o que justificaria a conclusão de que ambos os lados (tese e antítese) são falsos e, portanto, incapazes de provar o que pretendem.

Mas Kant tem de ir mais longe, já que esta constatação não acaba com a querela. Com efeito, as alternativas colocadas pelas antinomias não podem ser rejeitadas somente porque suas conclusões não assentam em "nenhum título sólido" (B529). Os gladiadores poderiam lançar mão de argumentos mais sólidos e assim decidir a contenda: "nada parece mais claro do que isto: de duas afirmações, uma que afirma que o mundo tem um começo e outra que sustenta que o mundo não tem começo e existe desde a eternidade, uma delas deverá ter razão" (idem). Noutros termos, todo o trajeto feito até aqui para dar cabo ao conflito é insuficiente para fazer os inimigos desistirem da luta. É preciso então dar um passo além e mostrar definitivamente que os gladiadores "disputam por nada e que uma certa aparência transcendental lhes representou uma realidade onde não a há. É este o caminho pelo qual vamos tentar por fim a uma contenda acerca da qual o tribunal não pode pronunciar-se" (B 52930 , grifo nosso). Noutros termos, o tribunal da razão se cala acerca da questão e não pode ir além de exigir também, por parte dos rivais, o silêncio. Entretanto, estes insistem na luta, porquanto não estão realmente convencidos da impossibilidade de defender suas posições. O que poderá detê-los? A estratégia kantiana, que abrirá campo à resolução das antinomias, envolverá então a apreciação do poder ontológico do negativo. 

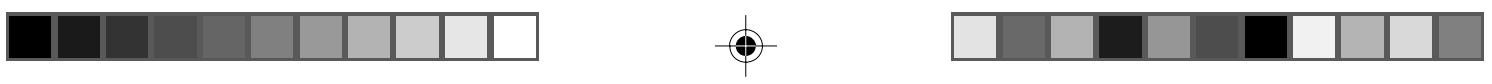

Silvana de Souza Ramos

\section{A arte de Zenão}

Zenão era o sofista atacado por Platão pelo fato de exercer a arte de "demonstrar qualquer proposição por meio de argumentos aparentes para, logo a seguir, derrubá-la por intermédio de outros igualmente fortes" (B 530). Por exemplo, demonstrava que Deus (o mundo) não era finito, nem infinito, que não estava em repouso, nem em movimento etc. Ora, diz Kant, "Quem o julgasse a este propósito era levado a crer que ele pretendia negar duas proposições contraditórias, o que é absurdo. Não me parece todavia que seja justa essa censura" (B 530, grifo nosso). Quer dizer, Kant defende a estratégia de Zenão na medida em que a maneira pela qual este desmonta as pretensões dogmáticas se assemelha à forma pela qual o filósofo alemão repreende a argumentação dos metafísicos: basta encenar ou "provocar" uma disputa para mostrar que nenhum dos lados é capaz de sustentar sua posição frente ao oponente. Zenão não deve ser censurado pois soube mostrar que há ocasiões em que dois lados em luta são igualmente falaciosos. Kant deixa de discutir imediatamente a alternativa finito ou infinito (vai tratá-la adiante), mas, para explicitar a justiça na argumentação de Zenão, afirma, por exemplo, que "se pela palavra Deus entendia o universo, tinha que dizer, sem dúvida, que este não está constantemente no mesmo lugar (em repouso), nem muda de lugar (não se move), porque todos os lugares estão no universo e este, por conseguinte, não está em nenhum lugar" (B 530). Note-se que o problema consiste no modo como se compreende o sujeito da proposição: o que, afinal, podemos afirmar sobre o universo? Que tipo de asserções podemos admitir a respeito deste pretenso objeto? Ora, a aparição de Zenão no início da seção 7 é bastante sugestiva e deixa evidente que a argumentação kantiana se 
desenvolverá no sentido de esclarecer os argüidores dos perigos que rondam os debates quando não se sabe muito bem do que se está falando. Surge aqui o primeiro dado que permite compreender o pretenso poder ontológico da contradição: "Se dois juízos opostos um ao outro pressupõem uma condição inadmissível, ambos se anulam, não obstante a oposição (que contudo não é uma autêntica contradição), porque fica suprimida a condição única que conferia valor a cada uma delas" (B 531, grifo nosso). Se se tratasse de uma autêntica contradição, uma afirmação deveria de anular a outra, e, ao mesmo tempo, demarcar sua própria validade. Haveria, portanto, como decidir entre elas. Por isso, Kant pode afirmar sem delongas que uma oposição não é sempre uma contradição autêntica, porquanto dois juízos opostos podem ser ambos falsos, desde que seja suprimida a condição que lhes confere valor.

O segundo exemplo dado por Kant é curioso, pois se trata de uma proposição empírica. "Se alguém disser: Todos os corpos cheiram bem ou não cheiram bem, verifica-se ainda uma terceira possibilidade, que é a de nenhum deles cheirar a nada (não ter cheiro) e então ambas as proposições contrárias podem ser falsas" (B 531). Analisemos o exemplo disjuntivo:

Ou todo corpo cheira bem.

Ou todo corpo não cheira bem.

$\mathrm{Na}$ verdade, não há aqui contradição porque a determinação introduzida pelos dois juízos aparentemente contrários não cobre todos os casos possíveis. Em outras palavras, se digo que todos os corpos cheiram bem ou cheiram mal, ambas as proposições podem ser falsas porque não abarcam toda a extensão do sujeito: os corpos que não têm cheiro ficam de fora e desmascaram a falácia dos oponentes. $\mathrm{O}$ que poderia ser exemplificado assim: 

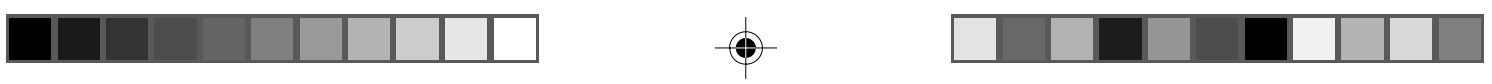

Silvana de Souza Ramos

Todos os corpos são odoríferos (cheiram bem ou não cheiram bem).

Alguns corpos não cheiram absolutamente nada.

Conseqüentemente, o conflito cheiroso-malcheiroso não tem poder sobre o conceito de corpo em toda a sua extensão e por isso não pode provar nada.

Segue-se um outro exemplo, também empírico: "se eu disser que todos os corpos são odoríferos ou não são odoríferos (vel suaveolens vel non suaveolens), os dois juízos são contraditórios entre si e só o primeiro é falso, mas o seu oposto contraditório, ou seja, alguns corpos não são odoríferos inclui os corpos que não cheiram absolutamente nada" (B 531). Vejamos:

Ou todo corpo é odorífero.

Ou todo corpo não é odorífero.

Ao contrário do exemplo anterior, os juízos, neste caso, são exaustivos e cobrem toda a extensão do sujeito (porque os corpos, quanto à condição acidental odorífera, ou são odoríferos ou não são odoríferos). Vejamos como opera a contradição entre eles (Kant diz que só o primeiro é falso):

Todo corpo é odorífero.

Algum corpo não é odorífero.

O oposto contraditório de "Todo corpo é odorífero" é "Algum corpo não é odorífero". Ora, o segundo inclui os corpos que não são odoríferos (excluídos no exemplo anterior). Aqui, a contradição é perfeita na medida em que é exaustiva, o que não ocorre com o conflito, no primeiro caso, entre cheiroso e malcheiroso.

Estes exemplos nos induzem a concluir que Kant defende a perfeição lógica da contradição ( $2^{\circ}$ exemplo) frente à falácia abarcada pelo conflito ( $1^{\circ}$ exemplo). Entretanto, como salienta David-Ménard, ao relacionar sujeito e predicado, o conflito deixa de fora de si mesmo 
uma certa ligação do sujeito e do predicado. Isto que fica de fora do conflito lógico é, surpreendentemente, o transcendental, isto é, o lógico em sentido redefinido, que pode apreender uma existência em lugar de ser apenas formal (tema tratado na discussão sobre a "anfibolia" ${ }^{2}$ ). Por isso, o conflito ocupa o mesmo lugar que o juízo indefinido em lógica, pois, segundo Lebrun, “o juízo indefinido é o instrumento da determinação completa" e, "se entendermos no sentido estrito o princípio 'omnis determinatio negatio' - ela [negação] é ao mesmo tempo qualificação para o ser finito, quer dizer, para o positivo enquanto ele é comparado a outros positivos" (Lebrun, p. 259, grifo nosso). Desse modo, ainda que a exclusão seja uma negação, a restrição - limitação - do conceito é um ato positivo. Assim, se digo que x é não-a, mostro que x pertence à esfera fora de $\mathrm{A}$. Evidentemente, isto só poderá ser compreendido depois de superado problema da antinomia, o que veremos adiante.

O exemplo posterior ao do corpo odorífero produzirá uma sutil modificação na marcha do argumento de modo a explicitar o que acabamos de dizer. Vimos que a existência é aquilo que o conflito lógico, no juízo indefinido, deixa de fora de si mesmo, ao fixar essa exterioridade através de um limite, o que é maneira mais rigorosa possível de determiná-la. Ora, nos raciocínios sobre o mundo, o uso da negação nas Antinomias deixa de fora de sua jurisdição a existência do mundo (como coisa em si). Por isso, o juízo indefinido põe em jogo a existência. Vejamos o exemplo (B 531-2):

Quando digo, pois: o mundo, quanto ao espaço, é infinito ou não é infinito (non est infinitus), se a primeira proposição é falsa, deve ser verdadeiro o seu oposto contraditório, a saber, o mundo não é infinito. Deste modo 

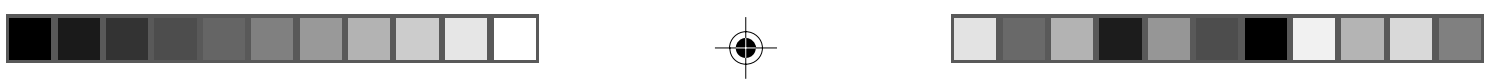

Silvana de Souza Ramos

só suprimiria um mundo infinito mas não poria outro, ou seja, o finito. Porém, se disser que o mundo é ou infinito ou finito (não-infinito) poderiam ambas ser falsas. Com efeito, vejo então o mundo determinado em si próprio, quanto à grandeza, porque na proposição oposta não só suprimo simplesmente a infinitude e, conjuntamente, talvez, toda a sua existência própria, mas também acrescento uma determinação ao mundo como a uma coisa real em si mesma, o que pode ser igualmente falso, se na verdade o mundo não devesse de modo algum ser dado enquanto coisa em si e, por conseguinte, nem como infinito nem como finito quanto à grandeza.

Em primeiro lugar, notamos que há uma inversão em relação aos exemplos anteriores (além do fato de que aqui não se trata de juízo empírico, mas de raciocínios cosmológicos). Primeiramente surge a negação contraditória: entre infinito e não infinito, um deve prevalecer. Entretanto, diferentemente dos juízos empíricos anteriores (odorífero e não-odorífero), a supressão de um não põe a existência do outro. Em outros termos, neste caso, a contradição é puramente formal, quer dizer, tem um poder supressivo, mas nenhum poder posicional. Ela aparenta ter, em relação ao mero conflito, o privilégio do rigor lógico, mas sob a condição de se mostrar sem efeito sobre a existência dos sujeitos lógicos aos quais concernem as proposições em que ela ocorre. Mas por que isso? Ora, exatamente porque o sujeito da proposição é o mundo, ou seja, algo que não pode ser subsumido como objeto a qualquer conceito. Em outras palavras, a contradição funciona formalmente, mas, como salienta Kant na "anfibolia": "Um uso puro das categorias - e é disso que se trata no exemplo - é, na 

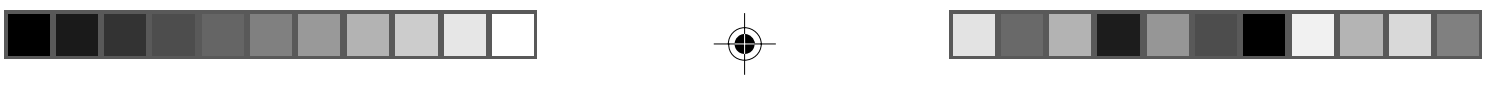

CAdernos Espinosanos XVI - 2007

verdade, possível, isto é, sem contradição, mas não possui nenhuma validade objetiva, pois não se refere a intuição alguma" (A 253, grifo nosso). Se a oposição contraditória (analítica) que acabamos de ver não ultrapassa o formalismo, ou seja, não tem nenhum poder ontológico ou posicional, que dizer da "oposição dialética"?

No exemplo citado acima, se digo que o mundo é ou infinito ou finito (não infinito), então "as duas proposições podem ser falsas". Ora, isto acontece, explica Kant, porque pressuponho um mundo "determinado", ou seja, o mundo como totalidade apreensível. Assim, se este pressuposto for negado, as duas proposições podem ser falsas: o mundo não é então nem finito nem infinito. Diferentemente do que ocorria na oposição analítica, o resultado da oposição dialética traz um saldo inesperado: ela mostra que há algo que o juízo deixa de fora, a saber, a própria existência do mundo. Este saldo é possível porque a reflexão revela a "aparência transcendental" que sustenta a oposição. Por conseqüência (B 532-3),

Se, porém, retirar este pressuposto ou esta aparência transcendental e negar que o mundo seja uma coisa em si, a oposição contraditória entre ambas as proposições transforma-se numa oposição simplesmente dialética e, como o mundo não existe em si (independentemente da série regressiva das minhas representações), não existe nem como um todo infinito em si, nem como um todo finito em si.

Tais observações podem nos ajudar a compreender a frase enigmática que antecipa essas conclusões: “Assim, dois juízos, dialecticamente opostos entre si, podem ser ambos falsos porque não só se contradizem, mas um deles diz mais do que é necessário para a 

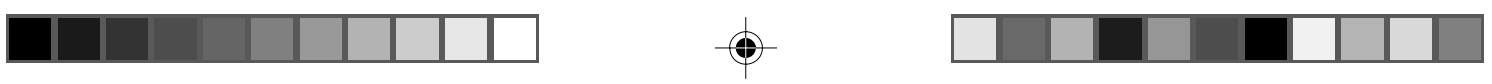

contradição" (B 532, grifo nosso). No conflito concernente à finidade ou infinidade do mundo, a contradição deve se limitar à sua validade formal, e não pretender por e depor o ser das coisas, ou seja, não deve pretender dizer "mais" do que lhe cabe. Entrementes, esta operação, expressa na negação conflitual, forma lógica do que é transcendentalmente uma oposição dialética, põe em jogo subrepticiamente - para falar com David-Ménard - a existência do sujeito pela mediação de uma determinação efetiva que lhe é imputada ("o mundo é determinado quanto à sua grandeza" implica a existência do mundo que se poderia caracterizar pela quantidade). Pois bem, o que permanece fora do alcance da negação no conflito não é uma condição acidental do sujeito - ser odorífero ou não odorífero, por exemplo - mas a existência do sujeito lógico sobre o qual raciocina o pensamento antinômico. Entretanto, justamente enquanto ilusão, a oposição dialética permite compreender as relações entre a negação e a posição de existência: pois ela diz algo mais do que se requer para a contradição. Nela, os juízos em conflito podem ser ambos falsos, porque incidem sobre um ser ao qual erroneamente atribuem existência.

Esta reflexão sobre a idéia cosmológica de grandeza do mundo pode ser aplicada a todas as outras idéias cosmológicas, pois, ao raciocinar sobre o mundo, o pensamento se refere sucessivamente a uma existência possível, e em seguida a uma existência constituída conforme as regras da experiência. A antinomia consiste no emprego de uma categoria, quer transcendental, quer empírica, de existência do mundo, por intermédio da suposição de sua determinação (quanto à grandeza, à simplicidade, à causalidade, à necessidade). A ilusão presente no raciocínio cosmológico só pode ser desmascarada pela análise transcendental, pois esta identifica que os juízos em conflito admitem uma condição inaceitável, o que lhes condena à falácia. 

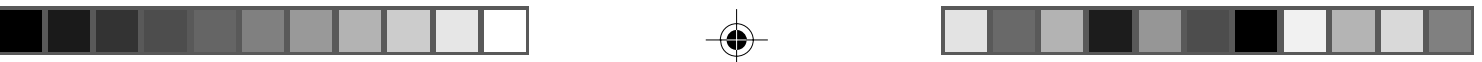

Cadernos Espinosanos XVI - 2007

\section{O papel objetivo da negação}

Haveria, entretanto, um bom uso da negação? Para responder a esta questão é preciso levar em conta os problemas enfrentados por Kant para orquestrar sua teoria da objetividade. Neste sentido, é preciso explicitar como podemos ter acesso à realidade, quer dizer, como podemos determinar uma existência singular ao invés de polemizar sobre o nada - ou seja, sobre a idéia de mundo. Este tema nos leva à oitava seção da Dialética Transcendental e ao tratamento que ela confere à noção de limite.

A seção 7 serviu para mostrar que pelo conceito cosmológico de totalidade não é "dado nenhum máximo à série de condições num mundo dos sentidos, considerado como coisa em si, e que este máximo apenas pode ser proposto como tarefa na regressão desta série" (B 536). Esta tarefa, ou este princípio, conserva sua validade, não como axioma para pensar como real a totalidade no objeto, mas como problema para o entendimento. Que isso quer dizer? Ora, a realidade dos objetos - no fenômeno - não pode ser alcançada mediante a regressão total na série empírica. Pois todo condicionado sugere a regressão à condição precedente, mas nunca ao incondicionado. A regra posta ao entendimento é, portanto, "um princípio que permite prosseguir e alargar a experiência o mais possível e segundo o qual nenhum limite empírico deverá considerar-se com o valor de limite absoluto" (B 537, grifo nosso). Por isso, tal princípio postula o que devemos fazer - como regra - na regressão, "mas não antecipa o que é dado em si no objeto antes de qualquer regressão" (idem). Noutros termos, ele não diz o que é o objeto antes da regressão, apenas sugere como essa regressão - sempre empírica - deve proceder de modo a "atingir o conceito completo de objeto" (B 538). Mas como 


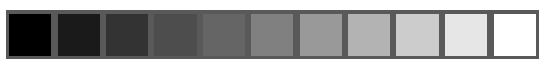

atingir o conceito completo do objeto? Neste ponto interfere uma distinção importante, surgida durante a análise, por Kant, da decomposição em partes (B 542):

Se o todo for dado empiricamente, é possível remontar até ao infinito na série das suas condições internas. Porém, se não for dado, ou se for dado unicamente pela regressão empírica só posso dizer: é possível, até ao infinito, ascender a condições cada vez mais altas da série. No primeiro caso poderia dizer que há sempre mais membros, e membros empiricamente dados, do que os que atinjo pela regressão (da decomposição); no segundo, porém, que posso avançar cada vez mais na regressão, porque nenhum membro é dado empiricamente como absolutamente incondicionado e admite, por conseguinte, sempre a possibilidade de um membro mais elevado e portanto a sua investigação como necessária.

Quer dizer, a determinação dos objetos reais somente é possível mediante a regressão empírica, e não necessita pressupor o mundo como objeto, ou seja, como totalidade dada em si. Simultaneamente, a regra limita o alcance fenomênico do objeto porque esclarece que sua determinação reside nas condições da sensibilidade, e não numa realidade - inacessível para nós - alheia à síntese temporal. Conseqüentemente, o objeto é aquilo que, modificando as condições da síntese que produz a idéia de mundo, torna possível a sua solução, de maneira deslocada. Em outros termos, o conhecimento do objeto por limitação ou restrição das condições nas quais é pensado o problema do mundo resolve essa idéia enquanto problema e propõe a tarefa da síntese empírica. Conseqüentemente, a crítica transcendental 


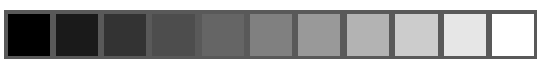

das antinomias nos leva à necessidade da idealidade transcendental dos fenômenos ou à compreensão de que só conhecemos aquilo que nos aparece, tal como nos aparece, segundo as regras de nossa sensibilidade.

Ora, que papel o negativo pode jogar aqui? Responder a tal pergunta exigiria alongar demais a discussão, porém, vale a pena situar a noção capital que serve para compreender este ponto: a idéia de oposição real. É ela que nos tira do embaraço da razão ao apontar um caminho preciso para o conhecimento: "construir objetos de conhecimento ao modo da oposição real em lugar de sonhar o mundo ao modo da oposição analítica ou da oposição dialética" (DavidMénard, p. 52). Segundo Lebrun, Kant opera uma cisão radical entre finito e infinito. A condição necessária da oposição real é a de operar entre dois conteúdos positivos, cuja conseqüência é zero (como no caso em que o repouso aparece como o resultado da destruição recíproca de duas forças motrizes). Noutros termos, os membros da oposição real são positivos e sua resultante (o repouso) é algo. Mas a oposição real é o lugar da determinação das coisas finitas: toda determinação é uma negação - a negação é a qualificação para o ser finito, quer dizer, para o positivo enquanto ele é comparado a outros positivos e não enquanto ele se refere ao infinito (por definição, indeterminado, o que no caso de Kant só pode significar vazio de conteúdo, porque não pode ser objeto de uma experiência). Isto nos permite terminar nossas reflexões indicando a distância desta formulação em relação às pretensões da fillosofia do XVII.

Kant toma o conceito de infinito no mesmo sentido que Espinosa [infinito como indeterminado], mas renuncia a um de seus princípios: 'dois positivos não podem excluirse', e apenas tira as conseqüências dessa recusa. A oposição 

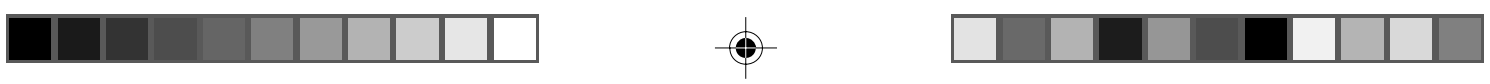

Silvana de Souza Ramos

simétrica entre os dois pensadores inscreve-se portanto em uma estrutura comum, e o abismo que separa um e outro do criacionismo é o signo dessa comunidade. Com efeito, tanto para Espinosa quanto para Kant a criação surge como um mistério que aquele recusa e este neutraliza. 'A criação concerne apenas à existência inteligível e não à existência sensível; assim, ela não pode ser considerada como princípio de determinação dos fenômenos' (Lebrun, p. 279).

A admissão da comparação entre as grandezas finitas como forma de determiná-las circunscreve uma formulação que seria inaceitável para Espinosa: admitir que algo no mundo sustente uma privação (como no caso em que o filósofo analisa o exemplo do cego). Entretanto, isto é perfeitamente aceitável para Kant, uma vez que o finito tem de ser determinado unicamente por referência ao finito (já que o fenômeno - como mostra a oposição real entre as coisas reais e a determinação completa - não se sustenta na existência do ser infinito).

\section{Bibliografia}

David-Ménard, M. A Loucura na Razão Pura. Kant leitor de Swedenborg. Trad. de H. B. S. Rocha. São Paulo: Editora 34, 1996.

Kant, I. Crítica da Razão Pura. Trad. de Manuela P. dos Santos e Alexandre F. Morujão. Lisboa: Fundação Calouste Gulbenkian, 2001. Essai pour Introduire en Philosophie le Concept de Grandeur

Négative. Trad. par R. Kempf. Paris: Vrin, 1991. 

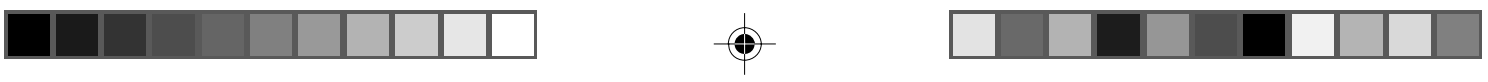

Cadernos Espinosanos XVI - 2007

Lebrun, G. Kant e o fim da metafisica. Trad. de Carlos A. R. e Moura. São Paulo: Martins Fontes, 1993 (Coleção Tópicos). . A Paciência do Conceito. Ensaio sobre o Discurso Hegeliano. Trad. de Silvio Rosa Filho. São Paulo: Ed. da UNESP, 2006.

Torres Filho, R. R. Ensaios de Filosofia Ilustrada. São Paulo: Brasiliense, 1987.

\section{Notas}

${ }^{1}$ Não discutiremos este aspecto, mas é importante sinalizar que, diferentemente do "tropeço da razão" que produz "idéias cosmológicas" sem qualquer validade empírica, "a totalidade absoluta na síntese das condições de todas as coisas possíveis em geral produzirá, ao contrário, um ideal da razão pura, que é totalmente distinto do conceito cósmico, conquanto se encontre em relação com ele" (B 435, grifo nosso).

2 "Mediante uma categoria pura, na qual se abstraiu de toda a condição da intuição sensível, única que nos é possível, não se determina nenhum objeto, apenas se exprime o pensamento de um objeto em geral, segundo diversos modos. Ora, para fazer uso de um conceito, é necessária ainda uma função da faculdade de julgar pela qual um objeto é subsumido no conceito, por conseguinte a condição pelo menos formal, pela qual algo pode ser dado na intuição. Se faltar esta condição da faculdade de julgar (o esquema), falta a subsunção, pois nada é dado que possa ser subsumido ao conceito" (B 304). 